\title{
An Investigation into Application of Dry Construction Technique in Providing Low-cost Housing for Nigerians
}

\author{
Adegbenga Raphael Ashiru ${ }^{1, *}$, Kamaldeen Jide Anifowose ${ }^{2}$ \\ ${ }^{1}$ Department of Building Technology, The Federal Polytechnic Kaura Namoda, Nigeria \\ ${ }^{2}$ Department of Architectural Technology, The Federal Polytechnic Kaura Namoda, Nigeria \\ *Corresponding Author: ashiruadegbenga@fedponam.edu.ng, ashiruadegbenga@yahoo.com, anifowosekamaldeen@gmail.com
}

Received June 15, 2020; Revised July 21, 2020; Accepted August 25, 2020

\begin{abstract}
Cite This Paper in the following Citation Styles
(a): [1] Adegbenga Raphael Ashiru, Kamaldeen Jide Anifowose, " An Investigation into Application of Dry Construction Technique in Providing Low-cost Housing for Nigerians, "Civil Engineering and Architecture, Vol. 9, No. 1, pp. 206 - 213, 2021. DOI: 10.13189/cea.2021.090117.
\end{abstract}

(b): Adegbenga Raphael Ashiru, Kamaldeen Jide Anifowose (2021). An Investigation into Application of Dry Construction Technique in Providing Low-cost Housing for Nigerians. Civil Engineering and Architecture, 9(1), 206 213. DOI: 10.13189/cea.2021.090117.

Copyright $\bigcirc 2021$ by authors, all rights reserved. Authors agree that this article remains permanently open access under the terms of the Creative Commons Attribution License 4.0 International License

\begin{abstract}
The significance of housing in mankind history cannot be overstressed. However, many Nigerian cannot afford to own a building due to high cost of building materials. Given the gaps, crises arising from shortage of low-cost housing necessitate a sustainable solution using new innovation and technology that is capable of fostering housing delivery. Due to high funding cost of capital projects in Nigeria and instability of crude oil price in the international market, the construction industry is in a tight spot to develop a cost-effective system of producing low-cost houses. It is in line with the above statement that this research was carried out to investigate the application of dry construction technique in providing low-cost housing for Nigerians. A quantitative approach was adopted that provided a wider understanding of the research based on the researcher's capability. The Statistical Package for the Social Sciences (SPSS Version 16) was used to obtain the descriptive and inference statistical analysis. Conclusively, the research results indicated that dry construction technique offered an outstanding opportunity to Nigerian government, citizens and the Primary Mortgage Institutions (PMIs) the assurance of prompt provision of low-cost housing by dropping the construction time to $70 \%$ and upturn housing supply. Therefore, government should look into the sustainability and socio-economic insinuation for provision of low cost housing in a supportive approach while stakeholders in construction industry should consider provider approach in bridging the housing deficit in Nigeria.
\end{abstract}

Keywords Construction Industry; National Housing Policy; Dry Construction; Construction Materials; and Application of DCT

\section{Introduction}

Access to secured, livable and safe shelter is a fundamental human right as preserved in the International Covenant on Economic, Social and Cultural Rights and Article 25 of the Universal Declaration of Human Rights. The 1999 Constitution of Federal Republic of Nigeria Section 43 also acknowledged the right of each Nigerian citizen to obtain property anywhere in Nigeria Adegboye [1].

Regardless of the current right, Nigeria is still facing the problem of low-cost housing provision for the low income employees which entails over $80 \%$ of Nigerian labor Adegboye [2]. In spite of formulation of various housing strategies by former and consecutive governments, the housing deficit continue to increase Esiowu [3]. The 1979 Shehu Shagari administration housing strategies was unsuccessful to meet the Nigerian housing needs due to absence of designs that enshrined different cultural description.

Although, the federal government vowed to deliver housing for all her citizens with an abbreviation of Housing for All by Year 2000 which wasn't successful. Nonetheless, 
existing housing deficit still remained high increase despite the formulation of 2012 housing policy which targeted provision of low-cost housing for low income earners in Nigeria Adegboye [2].

Presently, the APC- led government had begun the trial phase of National Housing Program (NHP) in Federal Capital Territory (FCT) and thirty four states with exemption of Rivers and Lagos and Rivers state governors who refused to release land for the project. Adegboye [2] stressed that the project is at a slow pace due to payment of funds to contractors and compensation to communities, though funds spent on the project were covered in privacy.

Given the lapses, (Ademilayi and Raji [4] maintained that the crises of low-cost housing deficits necessitate sustainable solution using advance innovation and technology that is able to accelerate housing delivery in Nigeria. Landlagos [5] also argued that due to high cost of funding capital projects in Nigeria, Nigerian construction industry is in the process of developing new cost and technology efficient system for provision low-cost housing away from the traditional method.

Further findings by researchers [1,3-6] have revealed that dry construction technique as a cost and technology efficient system may likely accelerate the provision of low-cost housing in Nigeria. Hence, a construction method that saves cost and time is what is currently obtainable globally and it is against this backdrop that this research was carried out to answer the fundamental research question:

- What is the relationship between Dry Construction Technique and provision of low-cost housing for Nigerians;

However, the research will only revolve round the application of dry construction technique in providing low-cost residential and non-residential for Nigerians.

\subsection{Objectives of the Study}

- To critically review literatures on dry construction techniques globally and investigates its process in the application of dry construction technique in Nigeria;

- To collect data from stakeholders on the application of dry construction techniques in Nigeria through questionnaire received from the case study;

- To critically analyze and summarize the findings from the data collected from the case study in order to examine the application of dry construction technique in Nigeria;

- To draw conclusion from the analysis of the data collected.

\subsection{Global Perception of Dry Construction Techniques (DCT)}

Dry construction market domain is largely determined by growing urbanization and industrialization and increasing acceptance of sustainable lightweight construction method by the construction industry. Allied Market Research [7] revealed that dry construction market has lately experienced exponential increase and believed this development will continue in the future. Esiowu [3] asserted that governments of numerous developed countries have accepted dry construction technique and have incorporated certain regulations in its sustainability.

However, dry construction market domain have been categorized by Allied Market Research [7] into five segments, namely- type, system, material, application, and geography According to type, the market is divided into boarding and supporting framework. Based on system, the market is divided into partition, walls, flooring, ceiling, windows and door systems. Based on construction material, the market is divided into wood, plastic, metals, plaster-wood, glass, and carpet. By application, the market is divided into residential and non-residential sector. The non-residential further divided into health care, commercial, hospitality etc. Geographically, the market is divided into America, Asia-Pacific, Europe and the LAMEA. Nevertheless, Allied Market Research [7] further predicted that China's dry construction market will become the fastest growing in coming years owing to its population growth and need for better housing technologies.

\subsection{Synopsis of Dry Construction Technique (DCT) Materials in Nigeria}

Nigeria introduced dry construction technique with the intention to reduce housing deficits in Nigeria Ademilayi and Raji [4]. The technique has become closely aligned with quick, quality and safe construction of internal and external element. Quick, quality performance and dry assembly that does not need any extra time for drying of the construction activities are significant advantages of this technique in Nigeria Adegboye [2].

Interestingly, researches have shown that dry construction technique could accelerate low-cost housing construction in Nigeria [1.2.3.5,6]. However, dry construction have also been seen as a construction technique in which core building components are fabricated in a factory and the finished products are assembled on construction site in dry condition without mortar in use $[1,2,5]$. It contrasts with the use of plaster, and the consequent drying out period.

Dry materials such as plywood and gypsum board are used as an alternative to plaster or concrete, bricks or blocks in dry construction. Ademilayi and Raji [4] further justified that the technique offers many benefits over wet construction practices such as reduction in construction time, ease of installation, better sound and thermal insulation, fire safety and moisture resistance as boards or panels could be fixed on metal structures to construct walls (exterior and interior), windows, ceilings etc.

A glance at numerous types of dry construction 
emphasised that the use of plaster boards is a substitute to a wet plaster application in the traditional technique of construction. A whole building may be dry walled in two days by skilled dry-Wallers as well as unprofessional carpenters. Another type of dry material used in dry construction is fiber cement made from cement, natural calcium, cellulose, quartz sand and water and further processed under high temperature and pressure for dimensional stability and durability Okeke [6].

To further justify this process, an innovative construction solution was launched in 2015 into Nigerian market by Nigerite Limited called Kalsi performance cement board. Kalsi Board are made from cement, natural calcium, cellulose, quartz sand and water and further processed through autoclave (under high temperature and pressure) for dimensional stability and durability [2.6]. The board are manufactured in numerous thickness and sizes ranging from $6 \mathrm{~mm}$ to $20 \mathrm{~mm}$ and produced under strict international standards and quality control.

Notwithstanding, dry material like Kalsi board for eave solution have been confirmed by construction professionals to contain high viable solution with faster, better technical finishes and lower self-weight because of its great thermal and acoustic properties, pest, moisture and fire resistance rating. Insulation boards, sandwich panel, spray foam, pre-cut pipe section and chemical system are among the Nigerite Limited's products for prefabricated structures using dry construction $(2,8]$.

In addition, metals including galvanised steel are also used as dry construction material where metals are shaped into frame and fixed onto an earlier finished foundation as postulated by Okeke [6]. He further asserted that curtain wall cladding and glass mat sheathing dry construction technique is progressively acknowledged nationwide because it is capital- intensive and are infrequently used as wall materials in low-cost housing. Expanded Polystyrene (EPS) dry construction material have also been acknowledged by practitioners where EPS panels are inserted between aluminum sheets to produce ready finished composite panels and could be used for both internal and external walls (Okeke, 2018)[6].

\subsection{Application of Dry Construction Technique in Nigeria}

Dry construction technique as a contemporary construction technique have transformed construction process to a manufacturing process and offers a design autonomy combined with complete infrastructure and technological cost. Adegboye [1] stressed that the technique is more adaptable and faster construction technique that dropped up to $70 \%$ construction time when compared with traditional construction technique. Through this construction process, Adegboye [2] affirmed that the processed construction products and materials are moved from the factory to construction site to achieved less infrastructure, technical and logistical costs.

Ademilayi and Raji [4] have earlier stressed that the technique is more environmental friendly, and reduces wastage, highly energy efficient, allowed easy pipes installation and other services. With this, The Nation [8] asserted that a new house accommodates comfortable room temperature and saves energy consumption low thereby improving the working and living environment of the inhabitants.

Ademilayi and Raji [4] maintained that the cost benefit and actual value of dry construction depend on the important factors such as cheap materials, minimal waste of materials, speed installations, low maintenance rating, load impacts on minimal excavation and lesser soil disturbance compared with traditional technique. Further to the above, Adegboye [2] affirmed that the technique consolidates better idea for green buildings in contemporary construction globally and produces a lightweight construction that has about ten times weight loss compared to traditional wet technique resulting to savings in structural and foundation cost.

Aligning with the new construction technique, scholars emphasised that the acceptance of this appropriate techniques and technology for low-cost housing development would certainly lower high housing cost and increase access to provision of housing for Nigerians $[2,6,7]$. They further encouraged federal government to implement the National Housing Fund (NHF) Act, 1992 provisions which is capable of attracting funds from numerous sectors of the economy especially from civil servants purse into the mortgage market Okeke [6]. Therefore, the technique presents an outstanding opportunity to government and Primary Mortgage Institutions (PMIs) a speedy provision of low-cost housing by dropping the construction time up to $70 \%$ and increase speedy access for Nigerians to own a house.

Although, the core problems of construction projects especially low-cost housing development in Nigeria as postulated by scholars and stakeholders are project cost, time constraint and standard of job delivery $[9,10]$. Therefore, there is urgent need for stakeholders to find ways of reducing project cost, time, maintain acceptable standard, and construct functional and sustainable structures with dignifying aesthetic and finishing through dry construction technique.

\section{Materials and Methods}

\subsection{Research Design}

Survey Research is the most appropriate research design for this study. This is associated with arranging an investigation to identify variables and their inter-relationships Farrell [11]. It also includes identification and investigation of social characteristics of 
the research subjects (respondents) Naoum [12]. For a given research must conform to the principles of the methodology and the information collected has to be from the representative of the area under study.

\subsection{Research Type}

The context of this research work is Exploratory and Descriptive. Exploratory research was used to collect data through literature review as well as existing studies on dry construction technique. Descriptive research was further used in an ordinary sense to describe events or situations and the intention is to collect existing data, analyse it and use the findings of such investigations to resolve existing problems thereby creating an objective basis for planning for the future resolution of similar problem. This further permits the researcher to analyse data collected from both primary and secondary data and described the findings to solve the research problem Saunders et al [13].

\subsection{Research Duration}

This is the time period from which the researcher started and ended the research. However, the research took Nine (9) months before completed. The activities carried out under the time frame includes- Literature Review, Development semi structure questions, Generation and Collection of Preliminary Data through questionnaire, Data Analysis of the questionnaires and Entering of data into Computer Data-Base, Testing and Justification of the developed framework with professionals in the field, and Writing up the Research which took three months.

\subsection{Inclusion/ Exclusion Criteria}

In descriptive research, specific group of relatively experts and professionals that are working directly on construction project were selected. Inclusion and exclusion criteria define who can be included or excluded from the study sample. The inclusion principles identify the study population in an objective, reliable, consistent and uniform manner. The exclusion principles include factors that make the engaged population unqualified for the study. For the purpose of this research, construction professionals who are not responsible for management of construction site on behalf of their organisation were excluded from participating in this research. This means that contractors, senior project managers were included as participants of the research.

\subsection{Choice of Subjects/Research Population}

The subjects comprised of experts and professionals that are working directly on construction project sites. They were participants who are senior project managers with the tasks of managing construction projects on behalf of their organisation within small and medium scale construction organisations in Kaduna, Nigeria. The subjects' permissions were sought for and assurance were given that their participation will be strictly confidential. However, twenty (25) construction small and medium enterprises were visited in the study area.

\subsection{Sampling Method}

Non-probability sampling was adopted as the sample method as this enables to select participants based on the research area. Bryman and Bell [14]. This assumed a purposive sampling strategy where respondents were selected at the discretion of the researcher but with the sole purpose to be typical of the whole population and the research question was best examined to evaluate participant engagement Saunders et al [13]. The sample size covered selected senior employees of clients, contractors, developers and consultants in small and medium scale Construction Company within Kaduna metropolis, Nigeria who are involved in construction project management at strategic level as Naoum [12] described this as a selected sampling process. Accordingly, sample size in quantitative research design is fundamental for the success of the research. Therefore, the merit of the quantitative research design is the ability to use a small sample size and to generalise it into a large sample.

\subsection{Sample Collection}

Data collection is a vital stage in gathering all essential data required to achieve the set objectives of the study. Therefore, the researcher mainly collected the primary data through a questionnaire survey that were distributed to selected senior employees of clients, contractors, developers and consultants in small and medium scale Construction Company within Kaduna, Nigeria who are involved in construction project management at strategic level. However, the secondary data were collected from various literature reviews in text books, articles, journals and websites with critical emphasis on dry construction technique locally and globally and the data were critically reviewed and used for the formulation of questionnaire. However, twenty five (25) questionnaires were distributed to selected participants but twenty two (22) responses were received back by the researcher covering $88 \%$ of the feedback. Lastly, the research instrument measures a reliability and validity test of 8.66 .

\subsection{Method of Data Analysis}

Quantitative method was adopted as the method of data analysis for this research because the quantitative research approach is precise, specific, and encourage large sample size which ensures feasibility in generalisation. The researcher obtained enough data through this method from the field in order to draw quality conclusions for the study. 
Cooper and Schindler [15] suggested that bias can be avoided through effective quantitative research methodology and will allow the respondents to freely express their knowledge about the subject matter as they respond to the research questions. However, a descriptive statistical approach was used to effectively analyse the results generated from the questionnaire and analysed through Statistical Package for the Social Sciences (SPSS-16) to obtain the descriptive and inference statistical analysis $[11,12]$.

\section{Results}

\subsection{Descriptive Statistics}

Table 1. Descriptive Statistics of the Data Collected

\begin{tabular}{|l|c|c|}
\hline & Mean & $\begin{array}{c}\text { Std. } \\
\text { Deviation }\end{array}$ \\
\hline Work Experience & 2.29 & 0.94 \\
\hline Gender & 1.07 & 0.26 \\
\hline Age & 3.36 & 0.62 \\
\hline Prevalence of DCT in Nigeria & 2.39 & 0.69 \\
\hline Direct Involvement in DCT & 2.36 & 0.95 \\
\hline Knowledge of DCT in Nigeria & 2.64 & 0.73 \\
\hline Training on DCT & 2.75 & 1.08 \\
\hline Waste Minimization Potential of DCT & 3.43 & 1.23 \\
\hline $\begin{array}{l}\text { Ease of Servicing Installations Potential } \\
\text { of DCT }\end{array}$ & 3.42 & 1.1 \\
\hline Energy Conservation Potential of DCT & 3.5 & 1.04 \\
\hline $\begin{array}{l}\text { Timely Project-Completion Potential of } \\
\text { DCT }\end{array}$ & 2.79 & 0.88 \\
\hline $\begin{array}{l}\text { Comparative Advantage DCT over } \\
\text { WCT }\end{array}$ & 3.39 & 0.79 \\
\hline $\begin{array}{l}\text { Housing construction Cost Reduction } \\
\text { Potential DCT }\end{array}$ & 3.35 & 0.99 \\
\hline $\begin{array}{l}\text { Minimal Impact on soil Disturbance } \\
\text { Potential DCT }\end{array}$ & 3.61 & 0.92 \\
\hline $\begin{array}{l}\text { Delay in Housing Completion \& } \\
\text { Delivery Challenge }\end{array}$ & 3.39 & 1.07 \\
\hline Housing Deficit & 4.39 & 0.07 \\
\hline
\end{tabular}

SPSS V16 (Field Survey, 2020)

From table 1 above, respondents have work experience ranging from 5-10 years (M 2.29; SD 0.94) and were dominated by male (M 1.07; SD 0.26) with average age within 25-31 years (M 3.36; SD 0.62). Respondents revealed that the prevalence of Dry Construction Technique (DCT) in Nigeria (M 2.39; SD 0.69) and their direct involvement in DCT is low (M 2.36; SD 0.95). Furthermore, they claimed that they possessed low knowledge (M 2.64; SD 0.73) and training (M 2.75; SD $1.08)$ on DCT. They opined that the potential of DCT was moderate with respect to Construction waste minimization (M 3.43; SD 1.23); Ease of servicing installations (M 3.42;
SD 1.10); Energy conservation (M 3.50; SD 1.04) and Minimal impact on soil disturbance (M 3.61; SD 0.92). They however reported that DCT ranks low with respect to the timeliness in housing project completion Potential (M 2.79; SD 0.88); moderately in Housing construction cost reduction (M 3.35; 0.99) and have comparative advantage over Wet Construction Technique (M 3.39; SD 0.79). Lastly, respondents claimed that there is currently a moderate lag in the completion and delivery of housing projects in the study area (M 3.39; SD 1.07) and affirmed that there is currently a huge housing deficit in Nigeria (M 4.39; SD 0.07).

\subsection{Hypothesis Testing}

H1: There is a significant relationship between Dry Construction Technique and low cost housing for all Nigerians.

H0: There is no significant relationship between Dry Construction Technique and low cost housing for all Nigerians.

Table 2a. The ANOVA Result of the relationship between the Potential of Dry Construction Technique (DCT) and Low-cost Housing Provision

\begin{tabular}{|c|c|c|c|c|c|}
\hline \multicolumn{7}{|c|}{ ANOVA } \\
\hline Model & $\begin{array}{c}\text { Sum of } \\
\text { Square }\end{array}$ & df. & $\begin{array}{c}\text { Mean } \\
\text { Squares }\end{array}$ & F & Sig. \\
\hline Regression & 9.982 & 1 & 9.982 & 12.204 & 0.002 \\
\hline Residual & 21.268 & 26 & 0.818 & & \\
\hline Total & 31.250 & 27 & $\mathrm{P}<0.05$ & & \\
\hline
\end{tabular}

a. Predictors: (Constant), Potentials of DCM

b. Dependent Variable: Housing Affordability

From table 2a above, the potential of DCT was found to have a significant relationship with measures of low-cost housing (F-12.204 \& Df 27). At P-value $<0.05$, the null hypothesis was rejected while the alternate hypothesis was accepted. This further justified the research question that there is a relationship between DCT and provision of low-cost housing for Nigerians.

Table 2b. The ANOVA result on the Predictive potential of Dry Construction Technique on Low-cost Housing provision

\begin{tabular}{|c|c|c|c|c|}
\hline \multicolumn{5}{|c|}{ Model Summary } \\
\hline Model & R & R-Square & $\begin{array}{c}\text { Adjusted } \\
\text { R Square }\end{array}$ & $\begin{array}{c}\text { Std. Error of the } \\
\text { Estimate }\end{array}$ \\
\hline 1 & $10.565^{\mathrm{a}}$ & 0.319 & 0.293 & 0.90443 \\
\hline
\end{tabular}

a. Predictors: (Constant), Potentials of DCM

Table 2C. Coefficients ${ }^{\mathrm{a}}$

\begin{tabular}{|c|c|c|c|c|c|}
\hline \multirow{2}{*}{ Model } & \multicolumn{2}{|c|}{$\begin{array}{c}\text { Unstandardized } \\
\text { Coefficients }\end{array}$} & $\begin{array}{c}\text { Standardized } \\
\text { Coefficients }\end{array}$ & \multirow{2}{*}{ T } & \multirow{2}{*}{ Sig. } \\
\cline { 2 - 4 } & B & Std. Error & Beta & & \\
\hline 1(Constant) & 0.239 & 0.879 & & & \\
Potentials of & 0.887 & 0.254 & 0.565 & 0.273 & 0.787 \\
DCM & & & 3.493 & 0.002 \\
\hline
\end{tabular}

a. Dependent Variable: Housing Affordability (Field Survey, 2020) 


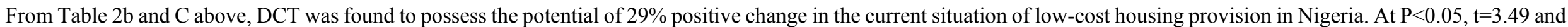
beta of 0.565 , such predictive power was found to be significant. However the model cannot explain the $71 \%$ change in the current situation of low-cost housing provision.

Table 3. Result of Spearman Correlation Coefficient of the Three Measures of Low-Cost Housing Provision and Seven Measures of Dry Construction Technique

\begin{tabular}{|c|c|c|c|c|c|c|c|c|}
\hline $\begin{array}{c}\text { Low-cost Housing } \\
\text { Measures }\end{array}$ & & $\begin{array}{c}\text { Waste } \\
\text { Minimization }\end{array}$ & $\begin{array}{l}\text { Ease of Servicing } \\
\text { Installed facilities } \\
\text { Potential }\end{array}$ & $\begin{array}{c}\text { Energy Efficiency } \\
\text { Potential }\end{array}$ & $\begin{array}{l}\text { Project Completion } \\
\text { Timeliness Potential }\end{array}$ & $\begin{array}{c}\text { Comparative } \\
\text { Advantage DCM } \\
\text { over }\end{array}$ & $\begin{array}{c}\text { Resource } \\
\text { Conservation } \\
\text { Potential }\end{array}$ & $\begin{array}{l}\text { Minimal impact On soil } \\
\text { Disturbance }\end{array}$ \\
\hline $\begin{array}{l}\text { Timely completion \& } \\
\text { Housing delivery }\end{array}$ & $\begin{array}{c}\text { Correlation } \\
\text { Coefficient } \\
\text { Sig. (2-tailed) }\end{array}$ & $\begin{array}{l}0.671 * \\
0.000\end{array}$ & $\begin{array}{c}0.323^{*} \\
0.094\end{array}$ & $\begin{array}{l}0.406^{*} \\
0.032\end{array}$ & $\begin{array}{l}0.394 * \\
0.038\end{array}$ & $\begin{array}{c}0.702^{*} \\
0.000\end{array}$ & $\begin{array}{c}0.476^{*} \\
0.010\end{array}$ & $\begin{array}{l}0.398^{*} \\
0.036\end{array}$ \\
\hline $\begin{array}{c}\text { Relative Reduction In } \\
\text { Housing Cost }\end{array}$ & $\begin{array}{c}\text { Correlation } \\
\text { Coefficient } \\
\text { Sig. (2-tailed) }\end{array}$ & $\begin{array}{l}0.681^{*} \\
0.000\end{array}$ & $\begin{array}{l}0.379 * \\
0.047\end{array}$ & $\begin{array}{l}0.491 * \\
0.008\end{array}$ & $\begin{array}{l}0.474 * \\
0.011\end{array}$ & $\begin{array}{l}0.597^{*} \\
0.001\end{array}$ & $\begin{array}{l}0.410^{*} \\
0.030\end{array}$ & $\begin{array}{l}0.523^{*} \\
0.004\end{array}$ \\
\hline Housing Deficit & $\begin{array}{l}\text { Correlation } \\
\text { Coefficient } \\
\text { Sig. (2-tailed) }\end{array}$ & $\begin{array}{c}0.671 * * \\
0.000\end{array}$ & $\begin{array}{l}\mathbf{0 . 3 2 3} \\
0.094\end{array}$ & $\begin{array}{l}0.406^{*} \\
0.032\end{array}$ & $\begin{array}{l}0.394 * \\
0.038\end{array}$ & $\begin{array}{l}0.702^{*} \\
0.000\end{array}$ & $\begin{array}{l}0.476^{*} \\
0.010\end{array}$ & $0.398^{*}$ \\
\hline
\end{tabular}

*. Correlation is significant at the 0.05 level (2-tailed).

(Field Survey, 2020)

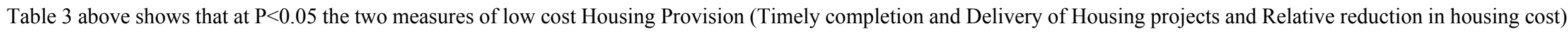

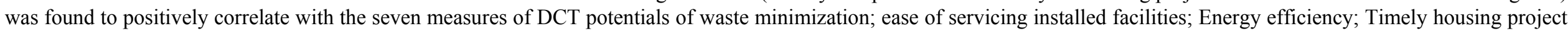

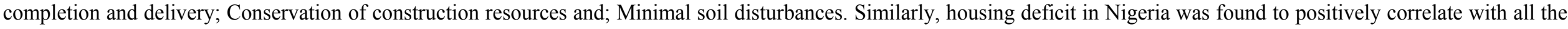
measures of DCT potential except for the measures of ease of installed facilities which was statistically insignificant. 


\section{Discussion}

The literature Adegboye [2] and empirical findings affirmed that there is a skill gap challenge in dry construction process and the industry should ensure that there is an upsurge in skill attainment with consistent training to guarantee the technology remains in Nigeria. However, the empirical findings and literature $[1,5,6]$ opined that with the enabling atmosphere in place, dry construction technique could reduce the housing shortfall in Nigeria. The enabling atmosphere includes finance, availability of land, inexpensive building materials, suitable institutional concept and sustainable construction workers.

As the literature $[1,5,6]$ highlighted that the core challenges of low cost housing development in Nigeria is the problem of project cost, standard of job delivery and time limit. The empirical findings revealed that DCT ranked moderately in Housing construction cost reduction and low with respect to the timeliness in housing project completion in the study area. This means that the field report in 2020 revealed how DCT have moderately reduced the housing project cost with less logistic, technical and infrastructure cost but agreed with the literature that more have to be done to increase standard of housing delivery and time limit in Nigeria.

More so, the literature [1,5] and the empirical findings moderately agreed that DCT have consistently reduced construction site waste and have attained less building energy consumption in Nigeria. Subsequently, explaining the comparative advantages of dry construction over wet construction technique, the literature $[1,5]$ and the empirical findings moderately agreed that DCT had speed up the construction process by delivering low cost houses faster and to standard. This allows early occupancy as traditional construction technique had failed to bridge the housing gap in Nigeria.

Lastly, the literature $[1,3,5,6]$ and the empirical findings highly agreed that despite the formulation of different housing policies by federal government, the housing deficit continued to increase. They further suggested that the government should look into the sustainability and socio-economic insinuation for provision of low cost housing in a supportive approach while stakeholders in construction industry should consider provider approach to bridge the housing deficit nationwide.

\section{Conclusions}

Dry construction technique offers an outstanding chance to Nigerian government and mortgage institutions an assurance for quick provision of low-cost housing in Nigeria. However, professionals in the construction industry through field survey strongly agreed that dry construction is the best alternative construction technique to bridge the desire gap in Nigerian housing provision. The findings further revealed that DCT is scarcely practiced in Nigeria but has the potential of managing the present challenges of low-cost housing provision in Nigeria through Timely housing project completion and delivery; conservation of construction resources; waste minimization; ease of servicing installed facilities; Energy efficiency and Minimal soil disturbances. Although, they noted that only dry construction technique cannot completely bridge the gap of housing shortfall in Nigeria. Interestingly, as the world is tending towards environmentally friendly practices in housing construction, DCT could discourage soil disturbances which have been so much associated with lots of health and environmental hazards. Comparatively, DCT could be cost effective in terms of servicing already installed facilities. With wide adoption of DCT, Housing constructions are speedily completed and delivered as the effective sequencing of project task are facilitated. The way forward as postulated by the literature and result from the field survey 2020 is for government to look into the sustainability and socio-economic insinuation for provision of low cost housing in a supportive approach through provision of land, sustainable policies and finance while stakeholders in construction industry should consider provider approach through provision of innovation and technology that is capable of fostering housing delivery in bridging the housing deficit in Nigeria. Conclusively, Dry Construction Technique could only account for $29 \%$ improvement in the present situation of low-cost housing provision in Nigeria. $71 \%$ change in the current situation in the provision of low-cost housing in Nigeria cannot be explained by the ANOVA result model of this study.

\section{Acknowledgements}

Glory to Almighty God who granted us the grace to successfully conclude this research work despite the challenges of COVID-19 Pandemic. Our profound gratitude goes to our beloved wives Mrs Morufat Kehinde Ashiru and Mrs Selimot Temitope Anifowose for their unrelenting support throughout this research work. We acknowledge the Heads of Departments (HOD) of Architectural and Building Technology Departments and colleagues for their incomparable support. Our profound gratitude and appreciation goes to the field professionals (respondents) for their suitable and productive suggestions towards the success of this research work.

\section{REFERENCES}

[1] K. Adegboye. Experts root for dry construction process to 
reduce housing shortfall [Online]. Available at: https://www.vanguardngr.com/2013/02/experts-root-for-dr y-construction-process-to-reduce-housing-shortfall/ Accessed: 21/11/2019. 2013

[2] K. Adegboye. Dry construction, solution to mass housing Nigerite boss [Online] Available at: https://www.vanguardngr.com/2015/02/dry-construction-s olution-mass-housing-nigerite-boss/ Accessed: 17/11/2019. 2015

[3] O.D. Esiowu. Dry Construction Method and Increased Housing Delivery Project [Online\}. Available at: https://www.propertypro.ng/blog/dry-construction-method -and-increased-housing-delivery-project/ Accessed: 25/10/2019. 2018

[4] A.I Ademilayi, B.A. Raji. Public and Private Developers as agents in Urban Housing delivery in Sub-Sahara Africa: The situation in Lagos State. Humanity and Social Science Journal Vol. 312. 2008

[5] Landlagos. Why Dry Construction Should Become Commonplace In Nigeria [Online] Available at: https://landlagos.com/blog/why-dry-construction-should-b ecome-commonplace-in-nigeria/ Accessed; 01/11/2019. 2019

[6] C. Okeke. Appraising Dry Construction Method For Increased Housing Delivery [Online]. Available at: htpp://Documents/Dry\%20Construction\%20Paper/Apprais ing $\% 20$ Dry $\% 20$ Construction $\% 20$ Method $\% 20$ For $\% 20$ Incr eased $\% 20$ Housing $\% 20$ Delivery\%20\%20Leadership $\% 20$ Newspaper.html Accessed: 14/12/ 2019. 2018

[7] Allied Market Research. World Dry Construction Market -
Opportunities and Forecast, 2020-2027 [Online] Available at: https://www.alliedmarketresearch.com/dry-construction -market. Accessed at; 26/02/2020. 2020

[8] The Nation. 'Dry construction can bridge housing gap' [Online] Available at: https://thenationonlineng.net/dry-co nstruction-can-bridge-housing-gap/ Accessed: 21/12/2019. 2013

[9] D.L. Anjiba and T.E Adu. Evaluation of Risk of Fluctuation Claim on Cost of Construction Projects in the South-South Zone of Nigeria. Civil Engineering and Architecture, 6(5), 252 - 256. DOI: 10.13189/cea.2018.060504. Accessed$14 / 02 / 2021.2018$

[10] M.K. Ahmed, F.S. Chang and W. Wahida. A Study on Factors Causing Cost Overrun of Construction Projects in Sarawak, Malaysia. Civil Engineering and Architecture, 8(3), 191 - 199. DOI: 10.13189/cea.2020.080301. Accessed- 13/02/2021. 2020

[11] P. Farrell. Writing a Built Environment Dissertation: Practical Guidance and Examples, 1st ed. United Kingdom: Blackwell. 2011

[12] S.G. Naoum. Dissertation Research and Writing for Construction Students. 3rd ed. London: Routledge. 2013

[13] M. Saunders, Thornhill, P. Lewis. Research Methods for Business Students. 5th ed. Harlow: Pearson Education Limited. 2009

[14] A. Bryman, E. Bell. Business Research Methods. 3rd ed. Oxford: Oxford University Press. 2011

[15] D.R. Cooper, P.S. Schindler. Business Research Methods, 9th ed. NY: McGraw-Hill. 200 